\title{
SUSTAINABLE REVERSE LOGISTIC NETWORK DESIGN FOR END-OF-LIFE USE-CASE STUDY
}

\author{
SunA CinAR*
}

\begin{abstract}
Due to the increased interests in environmental issues along with stringent environmental legislation and regulations, companies start taking a fresh look at the impact on their reverse logistic activties on the environment. This paper is an example of the recovery of valuable material that can be recycled/recovered or remanufactured at the end of product useful life by designing an effective reverse logistics network. In this study, a mixed integer linear programming (MILP) model is proposed to determine a long-term strategy for end-of-life (EOL). The mathematical model not only takes into account the minimization of system operating costs, but also considered minimization of carbon emissions related to the transportation and processing of used products. Therefore, the objective in this model was to minimize the transportation and operating cost as well as minimizing environmental effects these activities. The results of this study show the trade-off between the costs and carbon emissions, and cost effectiveness for improving environmental performance, all of which have great practical implication on decision-making of network configurations a reverse logistics system. The proposed model is validated by examining a case study from wind turbine (WT) sector.
\end{abstract}

Mathematics Subject Classification. 65C20.

Received November 29, 2018. Accepted June 20, 2019.

\section{INTRODUCTION}

Due to increasing environmental concerns, resource reduction, landfill capacity reduction, stricter government regulations, and global pressure to reduce carbon emissions, industries have started implementing end-of-life strategies in their reverse logistics network. Because reverse logistics by definition includes processes such as remanufacturing, refurbishment, recycling, reuse, and asset recovery, engaging in reverse logistics activities guarantees companies a certain level of green. Through effective reverse logistics operations, companies can also cut out inefficient returns processes that result in unnecessary transportation moves, helping to reduce carbon emissions and improve air quality [31].

Consideration of carbon policies while optimizing supply chain operations has become vital as governments and regulatory bodies throughout the world have implemented different carbon policies to reduce emissions of greenhouse gasses, especially carbon-dioxide $\left(\mathrm{CO}_{2}\right)$ emissions. The biggest international scheme for the trading of greenhouse gasses is European Union Trading Systems (EU-ETS), which was initiated in 2005, follows

Keywords. Mixed-integer linear programming, optimization, reverse logistic, end-of-life use, carbon emissions, environmental policy, climate control.

Department of Industrial and Manufacturing Engineering, Wichita State University, Wichita, KS 67260, USA.

*Corresponding author: cinarsuna@yahoo.com 
the "cap-and-trade" concept, where companies get an upper limit on emissions and beyond this limit, companies are penalized. In 1997, the Kyoto Protocol to the United Nations Framework Convention on Climate Change (UNFCCC) provided for carbon trading through three "flexible mechanisms" [40]. The Kyoto protocol introduced three major mechanisms for carbon emissions reduction: namely carbon trading and joint implementation [9]. The first mechanism serves as an economic incentive for companies to reduce carbon emissions. A central authority sets a limit (or CAP) on the permitted level of greenhouse gas emissions and allocates permits/allowances that bestow the right to emit greenhouse gases below the current or expected level of emissions [39]. The second and third mechanism allows countries to gain emission credits by financing emission reduction projects in developing countries and allows specified countries to carry out emission reduction projects in other countries to get emission credits [9].

As momentum builds to address climate change in every industry, the main objective of this study is to extend the existing mixed-integer-linear- program (MILP) [10] for a reverse logistic network design problem that is able to (1) consider both economic and environmental aspects to reduce the greenhouse gas emissions, and to (2) investigate the impact of two most common carbon regulatory policies such as carbon credit and carbon cap on reverse logistic operations in wind turbine (WT) industry.

In particular, there is a need for model-based research that extends and integrates current quantitative models which focus on minimizing cost by including carbon-footprint criteria under different policy situations. Therefore, the extended MILP model could then be used to understand how carbon emissions parameters affect operational decisions. Such model could help policy makers to choose different policies related to reduction of carbon emission such as using emission CAP and trade, taxes, etc.

This proposed model closes the research gap by contributing to the WT reverse logistic network literature in the following ways:

- The proposed MILP model is applicable to any types of assets. The model is illustrated on WTs over a finite horizon. Despite potential costs and benefits in optimally managing WTs, the literature does not consider the different emissions reduction options, which has enormous implications for expected and costs and environmental effects.

- Computational studies and detailed sensitivity analysis of the proposed MILP model are performed. The impact of key cost drivers of recycling, and remanufacturing as well as considering different carbon emission policies are analyzed to provide insights into an optimal reverse logistic network design for WT industry.

- The input data utilized in this study was gathered by employing various sources such as the literature and the opinions of WT operators and manufacturers. Therefore, this paper also provides detailed cost and asset replacement data to researchers and decision makers involved in WT industry.

- This paper provides a useful reference for wind farm operators involved in WT reverse logistic network decision making and could also be utilized as a decision support tool to minimize the total cost while considering reducing environmental effects.

The remainder of this paper is organized as follows. Section 2 presents athe literature review. A case study that used for the model application is given in Section 3. A description of the problem is outlined in Section 4, and the model notations, model assumptions, and models, which take the form of MILP, input parameters, and experimental set-up are then presented in Sections 4.1-4.6 respectively. Section 5 presents the model results and Section 6 provides a sensitivity analysis to provide interesting insights into the problem and demonstrate its utility for answering key research questions. Finally, Section 7 summarizes the findings and conclusions with recommendations for future research.

\section{Literature REVIEW}

In the last two decades, researchers have spent considerable effort studying how a reverse logistic can reduce cost, and how to establish an effective and efficient reverse logistics structure for different industries, such as automotive, electronics and recycling and reuse. Some of these studies conducted not only optimize the economic 
benefits of the well-designed reverse logistic network, but also optimize environmental performances of different operations areas under different carbon policies $[8,13,25,27,30,45]$. Some of these studies are summarized in the following section.

A MILP model was formulated to find an optimal strategy for companies to meet their carbon CAP, while minimizing costs by Diabat and Al-Salem [12]. Chaabane et al. [9] formulated a model of an aluminum firm and examined the carbon emissions impact on designing a sustainable close-loop-supply-chain (CLSC) network based on life-cycle-analysis (LCA) principles. They also evaluated the tradeoffs between economic and environmental dimensions under various cost and strategies. Fahimnia et al. [16] evaluated the forward and reverse supply chain influences on the carbon footprint using MILP model, where carbon emissions are demonstrated in terms of dollar carbon cost. Benjaafar et al. [5] illustrated the impact of carbon emissions and introduced a series of lot sizing models to be integrated into operations decisions and showed how significant emissions reductions without increases in costs can be achieved by operational adjustments alone.

Bing et al. [6] presented a reverse supply chain network, which was applied on household plastic waste distributed from Europe to China. A network optimization problem was modelled by using an integer programing approach, allowing the re-allocation of intermediate processing plants under emission trading restrictions. Emission trading restrictions were set on the processing plants in both Europe and China. Optimization results show that global relocation of re-processors leads to both a reduction of total costs and total transportation emission. With a given carbon cap, the model also showed the effective carbon price range. It was concluded that the model results can give an insight into the feasibility of building a global reverse supply chain for household plastic waste recycling.

Diabat and Al-Salem [12] addressed a joint location-inventory problem and extend it to account for the reduction of carbon emissions. They also considered the uncertainty by including a new variable that reflects the probability of different demand scenarios. Solved the problem, a genetic algorithm (GA) was developed. Based on the model run, it was determined that the resulting model was high in complexity and required solving within reasonable time.

Peng et al. [33] introduced a mixed integer linear programming formulation for modeling and solving a multiperiod one-stage supply chain distribution network design problem. The model was aimed to minimize two objectives, the total supply chain cost and the greenhouse gas emissions generated mainly by transportation and warehousing operations. Two carbon emissions regulatory policies were investigated, the tax or carbon credit and the carbon cap. Results demonstrated that for a certain range the carbon credit price incentivizes the reduction of carbon emissions to the environment. On the other hand, modifying the carbon cap inside a certain range could lead to significant reductions of carbon emissions while not significantly compromising the total cost of the supply chain.

Purohit et al. [33] studied the inventory lot-sizing problem under non-stationary stochastic demand condition with emission and cycle service level constraints considering carbon cap-and-trade regulatory mechanism. Using a MILP model, this study aimed to investigate the effects of emission parameters, product-and system-related features on the supply chain performance through extensive computational experiments to cover general type business settings and not a specific scenario. Results showed that cycle service level and demand coefficient of variation have significant impacts on total cost and emission irrespective of level of demand variability while the impact of product's demand pattern is significant only at a lower level of demand variability. The results of the study also show that increasing the value of carbon price reduces total cost, total emission and total inventory and the scope of emission reduction by increasing carbon price is greater at higher levels of cycle service level and demand coefficient of variation.

Yu and Solvang [44] provided an alternative approach to account both economic and environmental sustainability of reverse logistics system. The result of the study showed the trade-off between the costs and carbon emissions, cost effectiveness for improving environmental performance, and influences from resource utilization, all of which have great practical implication on decision making of network configurations and transportation planning of reverse logistics system. 
Rezaee et al. [36] presented a two-stage stochastic programming model to design a green supply chain in a carbon trading environment. The proposed model was applied to a real world case study. It was found that the supply chain configuration can be highly sensitive to the probability distribution of the carbon credit price. In addition, it was observed that carbon price and budget availability for supply chain reconfiguration can both have a positive but a nonlinear relationship with the greening of the supply chain.

$\mathrm{Xu}$ et al. [43] proposed a MILP method along with robust optimization to develop the model, which is validated using a sample case study of e-waste management. The model results showed that using a robust model by taking the complex interactions characterizing global reverse supply chain networks into account, which can create a better global-reverse-supply-chain (GRSC). The effect of uncertainties and carbon constraints on decisions to reduce costs and emissions were also shown.

Fang et al. [16] incorporated reverse logistics into production routing problems and investigated the reduction of carbon emissions under carbon cap-and-trade. A MILP model was proposed for the production routing problem with reverse logistics by considering simultaneous pickups and deliveries in vehicle routing subproblems. To solve this problem, a branch-and-cut guided search algorithm based on adaptation of known valid inequalities was proposed. Computational results showed that emission levels and operational costs of production, inventory holding, fuel consumption, and drivers were the main performance indicators.

Alkhayyal and Gupta [1] addressed the design of reverse supply chain under the three common regulatory policies, strict carbon caps, carbon tax, and carbon cap-and-trade. The model proposed can be used for designing and analyzing a reverse supply chain in a carbon trading environment, and optimize not only costs but also emissions in the supply chain operations. The model results showed that carbon tax emissions, particularly at higher taxes, affects transportation operations, which results in reduced transportation costs and emissions; whereas, the higher the carbon tax is, the lower emissions. It was concluded that applying an emissions cap combined with a carbon tax slightly increased total supply chain costs, but yielded a greener design.

Anvar et al. [2] developed a MILP to determine the amount of carbon emitted in a two-echelon supply chain in which one supplier delivers a single product to a group of retailers and attempts are made to integrate and coordinate its different members. The objective of this research was to minimize the costs of transportation and those engendered by material handling and inventory holding activities as well as to reduce carbon emissions throughout the supply chain. According to the results obtained, the supplier would opt for lower carbon vehicle types if replenishment timing, distances between members of the supply chain, the rate of carbon tax or the amount of retailers increases.

Ghosh et al. [19] developed an unconstrained mixed integer non-linear programming (MINLP) problem to find the optimal production rate, order quantity, number of shipments and reorder point while minimizing the total-expected-cost (TEC) of a two-echelon integrated supply chain with stochastic demand. Emissions from all the major sources such as production, inventory and transportation have been taken into consideration. It was assumed that the emission from production is a function of production rate, and emission from transportation depends on the payload and vehicle type. The aim of the proposed model to help organizations to reduce cost and emissions, and regulatory bodies to decide proper tax rate on carbon emissions.

Bottani and Casella [7] investigated the issue of minimizing the environmental burden of a real CLSC, consisting of a pallet provider, a manufacturer and several retailers. A simulation model was developed under Microsoft Excel to reproduce the flow of returnable transport items (RTIs) to compute the corresponding environmental impact. The results of the study showed that the asset retrieving operations contribute to the environmental impact of the system to the greatest extent due to a quite relevant distance between Company A and its customers. Conversely, emissions due to the purchase of new assets contributed to the total environmental impact of the system to a very limited extent. The results were expected to provide practical indications to logistics and supply chain managers, to minimize the environmental performance of the system.

In the literature, a significant number of studies focus on the RLND specially, facility location, production planning, green logistic, and end-of life use for different industries, such as automotive, electronics and recycling and reuse. On the other hand, to the best of our knowledge very little research has been done regarding WT end of life options under the cap and credit policy. This paper is going to address this gap by considering the 
uncertain recycling quality and quantity for modelling the low-carbon EOL management under these policies. Based on the environmental and economic factors, the supply chain would greatly benefit if the carbon emissions concept integrated into the whole reverse logistics network process. By doing so, the WT supply chain would become environmentally more responsible by recycling, reusing, or remanufacturing the WT. Therefore, we propose a model that can be used for designing and analyzing a reverse supply chain in a carbon trading environment, and optimize not only costs but also emissions in the supply chain operations. In addition. In this model, we propose to investigate the impact of the two most comman carbon regulatiry policies such as carbon emission cap and carbon tax on reverse logistic operations.

\section{Case Study Wind turbine And CARBOn EMissions}

Due to the increased awareness of environmental issues and more restrictive environmental regulations, renewable energy sources such as wind, solar, hydro, and geothermal are becoming more popular. The main driver for interest in WTs is to produce electrical power with very low $\mathrm{CO}_{2}$ emissions, which is one of the largest contributors of greenhouse gas emissions, the insidious cause of climate change [18].

Based on the environmental and economic factors, the supply chain would greatly benefit if a reverse logistics network was integrated into the whole supply chain process. By doing so, the WT supply chain would become environmentally more responsible by recycling, reusing, or remanufacturing the WTs reached their end-of-life (EOL) use. In addition, there is a possibility of economic gain from recycling and remanufacturing. Recovery of products and parts can be good alternatives to manufacturing new products and parts and virgin resources $[17,28]$. It is clear that an effective reverse logistics for WTs can generate direct gains by reducing the use of raw materials, adding value with recovery, reducing disposal costs, recycling to save landfill space and energy, and reducing $\mathrm{CO}_{2}$ emissions, in turn providing a more sustainable supply chain.

Life expectancy for WTs is about 20 years $[21,32]$. Due to increasing demand of using wind energy as a renewable energy source, at some point, many WTs will reach the end of their service life. Thus, a sustainable process that can be used when WTs reach the end of their service life is needed in order to maximize the environmental and economic benefits of wind energy and to minimize the environmental impact. In addition, because of the growing demand for energy in developing countries, and the interest in renewable energy sources, i.e., wind energy, which provides a sustainable and environmentally friendly power supply, remanufacturing of EOL WTs could be helpful to satisfy this growing need for power. Most of these developing countries may not be able to afford brand new WTs as a source of renewable energy. Therefore, providing used refurbished WTs in these locations offers several benefits, such as lower capital investment, shorter project duration, reduction of $\mathrm{CO}_{2}$ emissions, and a contribution to sustainable development [23].

Several studies discussed the reduction in $\mathrm{CO}_{2}$ by comparing different alternatives for treatment and replacement of old WTs. The highest amount of $\mathrm{CO}_{2}$ emissions for energy generation from WTs was found to be in the material production phase, which is $60 \%-64 \%$ of total emissions, and the next was in WT production. Transportation, disassembly, and renovation/maintenance contributes only $2 \%-3 \%$ of $\mathrm{CO}_{2}$ emissions [38]. Skrainka [41] analyzed the environmental impact of remanufacturing WTs and concluded that remanufacturing of the component inside the nacelle has a smaller impact on the environment than manufacturing new components. Arvesen and Hertwich [3] assessed the life-cycle environmental impacts of wind power and estimated that the EOL phase of WTs reduces emissions, decreasing greenhouse gas emissions by $19 \%$. Turbine $100 \mathrm{kWA}$ produced the majority of its emissions from manufacture, $30.6 \mathrm{tCO} 2 \mathrm{eq}(51 \%)$ and $28.7 \mathrm{tCO} 2 \mathrm{eq}(47 \%)$ from installation; transportation accounted for $1.18 \mathrm{tCO} 2 \mathrm{eq}(2 \%)$. For the $100 \mathrm{kWB}$ turbine, an installation made up the majority of emissions, $79.1 \mathrm{tCO} 2 \mathrm{eq}(59 \%)$; manufacturing accounted for 54 tCO2eq (41\%), and transportation accounted for $0.4[42]$.

The study, completed by Ghenai [18] shows the benefits of recycling parts of the WTs at the end life of their useful life, producing less $\mathrm{CO}_{2}$ than the landfilling process. It can be seen that the dominant phase that is consuming more energy and producing more $\mathrm{CO}_{2}$ emissions is the material phase and primary material production of the WT parts. More energy is consumed and high amount of $\mathrm{CO}_{2}$ is released into the atmosphere 
TABLE $1 . \mathrm{CO}_{2}$ emissions at different phase of WTs.

\begin{tabular}{lll}
\hline \hline Phase & $\mathrm{CO}_{2}(\mathrm{~kg})$ & References \\
\hline Remanufacturing & $1.2546 \mathrm{E}+006(\% 50$ of manufacturing emissions) & {$[1]$} \\
Recycling & $107669.7209(\% 20 \%$ of manufacturing emissions) & {$[1]$} \\
Landfilling & 13095.7080 & {$[1]$} \\
Transportation & $62 \mathrm{~g} \mathrm{CO}_{2} /$ tonne-km & {$[2]$} \\
Total & $1.4054 \mathrm{E}+006$ & \\
\hline
\end{tabular}

Notes. [1] Ghenai [18]. Life cycle analysis of wind turbine. Ocean and Mechanical Engineering Department, Florida Atlantic University. http://cdn.intechopen.com/pdfs/29930.pdf. [2] ECTA [14]. Guidelines for Measuring and Managing $\mathrm{CO}_{2}$ Emission from Freight Transport Operations. https://www.ecta.com/resources/Documents/Best\% 20Practices\%20Guidelines/guideline_for_measuring_and_managing_co2.pdf.

during these two phases. If all materials are sent to the landfill at the WT end of life, then $2.18 \mathrm{E}+011 \mathrm{~J}$ of energy ( $1.1 \%$ of total energy) is needed to process these materials, and $13095.71 \mathrm{Kg}$ of $\mathrm{CO}_{2}(0.9 \%$ increase of total $\left.\mathrm{CO}_{2}\right)$ are released to the atmosphere. If WT material is recycled at the EOL, then a total energy of $6.85 \mathrm{E}+012 \mathrm{~J}$ ( $54.8 \%$ of total energy) is recovered. A net reduction of $\mathrm{CO}_{2}$ emissions by $495917.28 \mathrm{Kg}(55.4 \%$ of total $\mathrm{CO}_{2}$ ) is obtained by recycling the WT material [18].

The average $\mathrm{CO}_{2}$-emission factor recommended by McKinnon for road transport operations is $62 \mathrm{~g}$ $\mathrm{CO}_{2} /$ tonne-km. This value is based on an average load factor of $80 \%$ of the maximum vehicle payload and $25 \%$ of empty running. The average $\mathrm{CO}_{2}$-emission factor recommended by McKinnon for calculation of $\mathrm{CO}_{2}{ }^{-}$ emission from rail transport operations is $22 \mathrm{~g} \mathrm{CO}_{2}$ /tonne-km [14]. Table 1 summarizes the $\mathrm{CO}_{2}$ emissions released during different phase of WTs production.

The model explained in Section 4 has been applied to the case of a RLND for EOL WTs. A five-echelon network consisting of 3 wind farms (generating plants) was considered for the model implementation. A simple illustration of the model - a single WT type with three components is considered. The remainder of this chapter is organized as follows. The mathematical model, the calculation of input parameters and application of the model are presented in detail in Section 4. All computational results for the base-case scenario and different scenarios are given in Section 5. Model sensitivity analysis are given in Section 6. Finally, some concluding remarks with future directions are provided in Section 7.

\section{REVERSE LOGISTICS NETWORK MATHEMATICAL MODEL}

The main objective of this model is to minimize the cost and carbon emissions associated with logistics and operating cost of different disposal options (i.e., recycling or remanufacturing) while minimizing carbon emissions for EOL products. The proposed model considers the design of a multi-echelon reverse logistics network that consists of collection centers, inspection centers, remanufacturing centers, recycling centers, and secondary market. Similar to previous study [10], the present study makes the following assumptions:

The following assumptions are made:

- Locations are known.

- Potential inspection, recycling, and remanufacturing centers

- Markets for recycling and remanufacturing

- Disposal centers

- There is no storage in the inspection/recycling and remanufacturing centers, therefore no holding cost.

- A fixed cost is associated with opening inspection, recycling, disposal, and remanufacturing centers.

- Transportation cost is determined per mile, and total transportation costs in the objective function are obtained by multiplying these costs by distances between two nodes. These distances are calculated by haversine formula [29]. 


\subsection{Model notation}

In order to propose our model for the problem, the sets, indexes, parameters, cost, and decision variables used in the model are given as follows:

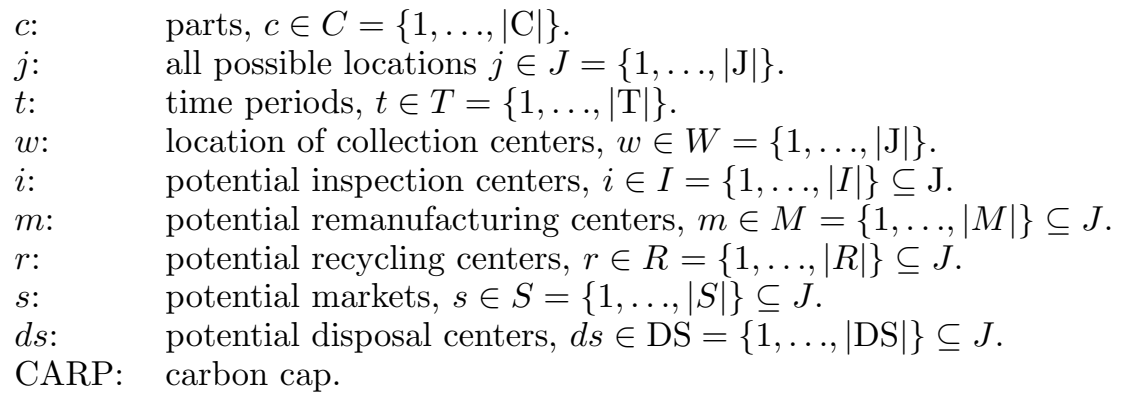

\section{Parameters}

$\begin{array}{ll}Q_{w c t}: & \text { supply of WT component } c \text { at wind farm } w \text { in period } t . \\ \mathrm{DSM}_{s c t}: & \text { demand of WT component } c \text { at market } s \text { in period } t . \\ \mathrm{DR}_{r c t}: & \text { demand of WT component } c \text { at recycling center } r \text { in period } t . \\ \mathrm{DM}_{m c t}: & \text { demand of WT component } c \text { at remanufacturing center } m \text { in period } t . \\ \mathrm{DL}_{d s c t}: & \text { demand of WT component } c \text { at disposal center } d s \text { in period } t . \\ \mathrm{CAPI}_{i t}: & \text { capacity of inspection center } i \text { in period } t . \\ \mathrm{CAPR}_{r t}: & \text { capacity of recycling center } r \text { in period } t . \\ \mathrm{CAPM}_{m t}: & \text { capacity of remanufacturing center } m \text { in period } t . \\ \mathrm{CAPD}_{d s t}: & \text { capacity of disposal center } d s \text { in period } t . \\ \alpha: & \text { \% of WT component } c \text { sent from inspection center to recycling center. } \\ \beta: & \text { \% of WT component } c \text { sent from inspection center to remanufacturing center. } \\ \gamma: & \text { \% of WT component } c \text { sent from inspection center to disposal center. }\end{array}$

\section{Costs}

$\mathrm{FI}_{i t}$ :

$\mathrm{FM}_{m t}$ :

$\mathrm{FR}_{r t}$ :

$\mathrm{FA}_{l t}$ :

$\mathrm{OI}_{c i t}$ :

$\mathrm{OR}_{c r t}$ :

$\mathrm{OM}_{c m t}$ :

$\mathrm{CI}_{\text {cit }}$ :

$\mathrm{CR}_{\text {crt }}$ :

$\mathrm{CM}_{c m t}$ :

$\mathrm{CA}_{\text {clt }}$ :

$T_{\text {wict }}, T_{i r c t}, T_{i m c t}, T_{m s c t}, T_{i l c t}$ :

$\theta:$

$\Omega$ :

$d r:$ fixed cost opening inspection center $i$ in period $t(\$)$.

fixed cost opening remanufacturing center $m$ in period $t(\$)$.

fixed cost of opening recycling center $r$ in period $t(\$)$.

fixed cost of opening disposal center $l$ in period $t(\$)$.

cost of processing one unit of WT component $c$ at inspection center $i$ in period $t(\$)$.

cost of processing one unit of WT component $c$ at recycling center $r$ in period $t(\$)$.

cost of processing one unit of WT component $c$ at remanufacturing plant $m$ in period $t(\$)$.

$\mathrm{CO}_{2}$ emission indicator of processing one unit of WT component $c$ at inspection center $i$ in period $t$ (gram).

$\mathrm{CO}_{2}$ emission indicator of processing one unit of WT component $c$ at recycling center $r$ in period $t$ (gram).

$\mathrm{CO}_{2}$ emission indicator of processing one unit of WT component $c$ at remanufacturing plant $m$ in period $t$ (gram).

$\mathrm{CO}_{2}$ emission indicator of processing one unit of WT component $c$ at disposal center $m$ in period $t$ (gram).

transportation distance of one unit of WT component $c$ at time period $t$ from $w$ to $i, i$ to $r, i$ to $m, m$ to $s$, or $i$ to $l$ (mile).

unit transpiration cost factor $(\$ /$ mile).

unit carbon emissions factor (gram/unit-mile) total $\mathrm{CO}_{2}$ emissions/\# units.\# km's.

inflation rate. 


\section{Decision variables}

$X 1_{\text {wict }}$ : number components $c$ shipped from wind farm $w$ to inspection center $i$ in period $t$.

$X 2_{\text {imct }}$ : number components $c$ shipped from inspection center $i$ to remanufacturing center $m$ in period $t$.

$X 3_{i r c t}$ : number of components $c$ shipped from inspection center $i$ to recycling center $r$ in period $t$.

$X 4_{m s c t}$ : number of components $c$ shipped from remanufacturing center $m$ to market $s$ in period $t$.

$X 5_{i l c t}$ : number of components $c$ shipped from inspection center $i$ to disposal center $l$ in period $t$.

\section{Binary variables}

$Y_{i t}=\left\{\begin{array}{lr}1 & \text { if an inspection center } i \in I \text { is operating in period } t \in T, \\ 0 & \text { otherwise. }\end{array}\right.$

$Z_{m t}=\left\{\begin{array}{lr}1 & \text { if a remanufacturing center } m \in M \text { is operating in period } t \in T, \\ 0 & \text { otherwise. }\end{array}\right.$

$U_{r t}=\left\{\begin{array}{lr}1 & \text { if a remanufacturing center } r \in R \text { is operating in period } t \in T, \\ 0 & \text { otherwise. }\end{array}\right.$

$A_{l t}=\left\{\begin{array}{lr}1 & \text { if a disposal center } l \in L \text { is operating in period } t \in T, \\ 0 & \text { otherwise. }\end{array}\right.$

\subsection{Mathematical model}

The model proposed in this study is an extension to the reverse logistic network design problem proposed by Cinar and Yildirim [10]. In their study, the objective is to minimize the transportation and operating cost as well as finding the best locations for recycling and remanufacturing centers by using MILP. The main objective of their model is to minimize the cost associated with logistics and operating cost of different disposal options (i.e., recycling or remanufacturing) for EOL products. Based on their model findings, it is concluded that in addition to transportation cost, operating cost is also one of the main cost contributors to overall reverse logistics cost. Their model helps decision makers to choose the most suitable disposal method with the remanufacturing and recycling alternatives. In their model, the cost is only driving force for decision making process; therefore, the RLND would greatly benefit if the carbon emissions concept is integrated into the whole reverse logistics network process. There is a need for model-based research that extends quantitative models, which typically focus on either minimizing cost or maximizing profit, to include carbon footprint. Therefore, we propose a model that can be used to understand how accounting for carbon emissions (either as a constraint or as a decision criterion) might affect operational decisions. We extend on Cinar and Yildirim [10] by introducing an optimization model, where the economic profitability and the carbon emission issue are simultaneously considered. Furthermore, two different carbon emission policies are analyzed. This extended model can also be used to inform operations managers on how policies, such as mandatory emission caps, taxes on carbon emissions, and emission cap-andtrade, among others, ought to affect operational decision-making. As a results, in our model, we presents two extensions of the RLND model formulation to capture the environmental impact that different carbon regulatory policies have on the RLND and logistics decisions. These policies include (1) carbon cap where companies are subject to mandatory caps on the amount of carbon they emit; (2) carbon tax where companies are taxed on the amount of carbon emissions they emit or get credit when emit less than the regulated amount of carbon. The carbon emissions of reverse logistics include two parts: carbon emissions from processing of used products and carbon emissions from the transportation. By adding carbon tax and/or carbon cap, our purpose to minimize total carbon emissions which is produced by transportation and during operations.

\subsection{Model 1: Model with carbon emissions consideration}

In the following model, the objective is to minimize the environmental influences of the reverse logistic network. Under the carbon cap policy, $\mathrm{CO}_{2}$ emissions from processing of used products and carbon emissions from transportation have a limited amount of carbon allowance (in ton) to use, which is referred to as carbon cap. 


\section{Basic model formulation}

Minimize $Z 1=Z_{11}+Z_{12}+Z_{13}$.

Fixed cost $Z_{11}=$

$$
\begin{aligned}
& \sum_{i} \sum_{t} \mathrm{FI}_{i t} *\left(Y_{i t}-Y_{i, t-1}\right) *(1+d r)^{-t}+\sum_{m} \sum_{t} \mathrm{FM}_{m t} *\left(Z_{m t}-Z_{m, t-1}\right) *(1+d r)^{-t}+\sum_{r} \sum_{t} \mathrm{FR}_{r t} *\left(U_{r t}\right. \\
& \left.\quad-U_{r, t-1}\right) *(1+d r)^{-t}+\sum_{l} \sum_{t} \mathrm{FA}_{l t} *\left(A_{l t}-A_{l, t-1}\right) *(1+d r)^{-t} .
\end{aligned}
$$

Transportation cost $Z_{12}=$

$$
\begin{aligned}
& \sum_{t} \sum_{c} \sum_{w} \sum_{i} T_{\text {wict }} * \Theta * X 1_{\text {wict }} *(1+d r)^{-t}+\sum_{t} \sum_{c} \sum_{i} \sum_{m} T_{i m c t} * \Theta * X 2_{\text {imct }} *(1+d r)^{-t} \\
& \quad+\sum_{t} \sum_{c} \sum_{i} \sum_{r} T_{i r c t} * \Theta * X 3_{\text {irct }} *(1+d r)^{-t}+\sum_{t} \sum_{c} \sum_{m} \sum_{s} T_{m s c t} * \Theta * X 4_{m s c t} *(1+d r)^{-t} \\
& \quad+\sum_{t} \sum_{c} \sum_{i} \sum_{l} T_{i l c t} * \Theta * X 5_{i l c t} *(1+d r)^{-t} .
\end{aligned}
$$

Operations and disposal cost $\mathrm{Z}_{13}=$

$$
\begin{aligned}
& \sum_{t} \sum_{c} \sum_{w} \sum_{i} \mathrm{OI}_{c i t} * X 1_{\text {wict }} *(1+d r)^{-t}+\sum_{t} \sum_{c} \sum_{i} \sum_{m} \mathrm{OM}_{c m t} * X 2_{i m c t} *(1+d r)^{-t}+\sum_{t} \sum_{c} \sum_{i} \sum_{r} \mathrm{OR}_{c r t} \\
& * X 3_{\text {irct }} *(1+d r)^{-t}+\sum_{t} \sum_{c} \sum_{i} \sum_{l} \mathrm{OA}_{c s t} * X 5_{i l c t} *(1+d r)^{-t} .
\end{aligned}
$$

The followings are the constraints of the basic model:

$$
\begin{aligned}
& Q_{w c t}=\sum_{i \in I} X 1_{w i c t} \quad w \in W, c \in C, t \in T \\
& \alpha+\beta+\gamma=1 \\
& \sum_{w \in W} \alpha * X 1_{w i c t}=\sum_{m \in M} X 2_{i m c t} \quad i \in I, c \in C, t \in T \\
& \sum_{c \in C} \gamma * X 1_{\text {cipt }}=\sum_{l \in L} X 5_{\text {ilct }} \quad i \in I, c \in C, t \in T \\
& \sum_{w \in W} \beta * X 1_{w i c t}=\sum_{r \in R} X 3_{i r c t} \quad i \in I, c \in C, t \in T \\
& \sum_{s \in S} X 4_{m s c t}=\sum_{i \in I} X 2_{i m c t} \quad m \in M, c \in C, t \in T \\
& \sum_{s \in S} X 4_{m s c t} \leq \sum_{s \in S} \operatorname{DSM}_{s c t} \quad m \in M, c \in C, t \in T \\
& \sum_{r \in R} X 3_{i r c t} \leq \sum_{r \in R} \mathrm{DR}_{r c t} \quad i \in I, c \in C, t \in T \\
& \sum_{m \in M} X 2_{i m c t} \leq \sum_{m \in M} \mathrm{DM}_{m c t} \quad i \in I, c \in C, t \in T \\
& \sum_{l \in L} X 5_{i l p t} \leq \sum_{l \in L} \mathrm{DL}_{l c t} \quad i \in I, c \in C, t \in T \\
& \sum_{w \in W} \sum_{c \in C} X 1_{w i c t} \leq \mathrm{CAPI}_{i t} * Y_{i t} \quad i \in I, t \in T
\end{aligned}
$$




$$
\begin{array}{rl}
\sum_{i \in I} \sum_{c \in C} X 3_{i r c t} \leq \mathrm{CAPR}_{r t} * U_{r t} & r \in r, t \in T \\
\sum_{i \in I} \sum_{c \in C} X 2_{i m c t} \leq \mathrm{CAPM}_{m t} * Z_{m t} & m \in M, t \in T \\
\sum_{i \in I} \sum_{c \in C} X 5_{i l c t} \leq \mathrm{CAPD}_{l t} * A_{l t} & l \in L, t \in T \\
Y_{i t} \in\{0,1\}, Z_{m i} \in\{0,1\}, U_{r t} \in\{0,1\}, A_{l t} \in\{0,1\} & \\
Y_{i t} \leq Y_{i, t+1}, X 3_{\text {irct }}, X 4_{m s c t}, X 5_{i l c t} \geq 0 & i \in I, r \in R, M \in M, t \in T, l \in L \\
U_{r t} \leq U_{r, t+1} & r \in R, t \in T \\
Z_{m t} \leq Z_{m, t+1} & m \in M, t \in T \\
A_{l t} \leq Z A_{l, t+1} & l \in L, t \in T .
\end{array}
$$

Constraint (2) is a flow balance constraint which is the number of disassemble WTs parts at wind farms (generation points) equal to the number of WT parts sent to inspection centers. Constraint (3), the total ratio of components that are sent to recycling, remanufacturing, and disposal centers, is equal to one. Constraints (4)-(6) model the flow balance between inspection centers, and recycling, remanufacturing and disposal centers, i.e., the total number of WT components at the inspection centers is equal to number of WT components shipped to recycling, remanufacturing and disposal center. Constraint (7) shows the total inflow component coming from remanufacturing centers is equal to the outflow of WTs sold to secondary market. Constraint (8) formulates the number of WTs sold to the secondary market are no more than the demand for the remanufactured WTs at each time period. Constraint (9) assures that the number of WT components sent to a recycling center is no more than the demand of component at each time period. Constraint (10) ensures that the amount of WT component sent to remanufacturing center is no more than the demand of component at each time period. Constraint (11) ensures that the amount of WT component sent to disposal center is no more than the demand of component at each time period. Constraint (12) is the capacity constraint for production in the inspection center. Constraint (13) is the capacity constraint for production in the recycling center. Constraint (14) is the capacity constraint for production in the remanufacturing center. Constraint (15) is the capacity constraint for the disposal center. Constraint (16) is the non-negativity constraint, and constraint (17) is the integrality constraint. Constraints (18)-(21) ensure that once a center is installed, it remains operating until the end of the planning horizon.

\section{Model 1 (Extended model)}

The Model 1 (extended model) consists of basic model objective function, constraint (2) through constraint (21), and additional constraint (22) which represents the sum of emissions within the facilities and emissions due to transportation activities which should be less than or equals to the amount of carbon cap allowed.

$$
\begin{aligned}
\sum_{t} \sum_{w} \sum_{c} & \sum_{i} T_{\text {wict }} * \Omega * X 1_{\text {wict }} *(1+d r)^{-t}+\sum_{t} \sum_{c} \sum_{i} \sum_{r} T_{i r c t} * \Omega * X 3_{\text {irct }} *(1+d r)^{-t} \\
& +\sum_{t} \sum_{c} \sum_{i} \sum_{m} T_{i m c t} * \Omega * X 2_{\text {impt }} *(1+d r)^{-t}+\sum_{t} \sum_{c} \sum_{m} \sum_{s} T_{i m c t} * \Theta * X 4_{m s c t} \\
& *(1+d r)^{-t}+\sum_{t} \sum_{w} \sum_{c} \sum_{i} \mathrm{CI}_{c i t} * X 1_{\text {wict }} *(1+d r)^{-t}+\sum_{t} \sum_{c} \sum_{i} \sum_{m} \mathrm{CM}_{c m t} * X 2_{i m p t} \\
& *(1+d r)^{-t}+\sum_{t} \sum_{c} \sum_{i} \sum_{r} \mathrm{CR}_{c r t} * X 3_{\text {irct }} *(1+d r)^{-t}+\sum_{t} \sum_{l} \sum_{c} \sum_{i} \mathrm{CA}_{c l t} * X 5_{i l c t} \\
& *(1+d r)^{-t} \leq \mathrm{CARP} .
\end{aligned}
$$




\subsection{Model 2: Model with carbon emission CAP and carbon credit policy}

In the following model, the objective is to minimize the total network cost under carbon emission cap/credit policy. Under the carbon emission cap policy, there is a restriction on emissions and emission is penalized by using a carbon tax (penalty per unit of carbon emissions). This means that for every tonne of carbon dioxide emitted into the atmosphere, the producer may sacrifice a certain amount of capital. In terms of carbon credit, one carbon credit (or carbon "offset") is a closely regulated certificate representing a reduction of one metric ton of carbon dioxide being released into the atmosphere. In dollar terms, the price of carbon credits per ton is about USD 15 to USD 40 [22].

Minimize Model $2=$ Model $1+$ cost of carbon emissions credit in $\$$ per ton $\mathrm{CO}_{2} *$ (Total $\mathrm{CO}_{2}$ emissionCarbon emission cap (CARP))

Total Carbon Emissions =

$$
\begin{aligned}
& \sum_{t} \sum_{p} \sum_{c} \sum_{i} T_{\text {cipt }} * \Omega * X 1_{\text {cipt }} *(1+d r)^{-t}+\sum_{t} \sum_{c} \sum_{i} \sum_{r} T_{i r c t} * \Omega * X 3_{\text {irct }} *(1+d r)^{-t} \\
& \quad+\sum_{t} \sum_{c} \sum_{i} \sum_{m} T_{i m c t} * \Omega * X 2_{\text {imct }} *(1+d r)^{-t}+\sum_{t} \sum_{c} \sum_{m} \sum_{s} T_{m s c t} * \Theta * X 4_{m s c t} *(1+d r)^{-t} \\
& \quad+\sum_{t} \sum_{c} \sum_{i} \sum_{m} \mathrm{CM}_{c m t} * X 2_{\text {imct }} *(1+d r)^{-t}+\sum_{t} \sum_{c} \sum_{i} \sum_{r} \mathrm{CR}_{c r t} * X 3_{\text {irct }} *(1+d r)^{-t} \\
& \quad+\sum_{t} \sum_{p} \sum_{c} \sum_{i} \mathrm{CI}_{c i t} * X 1_{\text {cipt }} *(1+d r)^{-t} .
\end{aligned}
$$

Subject to:

Constraints (2)-(21) except constraint (22).

\subsection{Input parameters}

For each wind farm location, the number of WTs is determined randomly, and the distance matrix is created between 5 wind farm locations. It is assumed that three types of WT components are sent to each center. The cost data summarized in Table 2 is used for this study.

\subsection{Experimental design}

In this section, we present a RLND for one type WT under different cases by solving the proposed model. We perform all computational experiments on a personal computer equipped with Windows 7, 1:80 GHz CPU and 4 GB memory. This model is coded in the Generic Algebraic Modeling System (GAMS) as a front-end interface to CPLEX optimizer, which is used for solving MIP model over a 50-period (year) horizon.

To illustrate how the proposed MILP model can help wind farm operator to make optimal recycling/remanufacturing decisions, real world WT cost data is analyzed and incorporated into the model. We carried out scenario analysis, including three different cases, to understand how different disposal options affect the WTs RLND. Before giving the model results, it would be ideal to explain the each Case/Scenario.

For the initial base run for both Model-1 and Model-2, it was assumed that 30\% of the total supply would be remanufactured, $60 \%$ would be recycled and the remaining $10 \%$ of the parts would go to disposal centers. It was assumed that this is not the case for all WTs, since several factors may affect their remaining life and that some of the WTs may still be in good conditions, or vise versa. Therefore, several other scenarios were modelled using ratio $(\alpha)$ values between 0.1 and 0.8 , in increments of 0.1 , to evaluate the effects of recycling/remanufacturing costs during the decision-making process.

The sensitivity analysis for Model-1 and Model-2 involved the investigation of the impact of carbon emissions rate, carbon cap amount and carbon credit provided for each $\mathrm{kg} \mathrm{CO}_{2}$, which is not emitted to the atmosphere. 
TABLE 2. Summary of cost data.

\begin{tabular}{|c|c|c|c|}
\hline & Item & Cost & Reference \\
\hline \multicolumn{2}{|l|}{ Transportation cost } & $\$ 4.2$ per mile & {$[4]$} \\
\hline \multicolumn{2}{|c|}{ New wind turbine cost (GE 1.5 XLE 1.5 MW } & $\$ 1400000$ & {$[2],[3]$} \\
\hline \multicolumn{2}{|c|}{ Remanufactured turbine cost (GE 1.5 SL) } & $\$ 500000$ & {$[2],[3]$} \\
\hline \multirow[t]{3}{*}{ Operating Cost } & $\begin{array}{l}\text { Operating cost at remanu- } \\
\text { facturing center }\end{array}$ & {$[\$ 10000-\$ 50000]$} & $\begin{array}{l}\text { Estimated based on expert } \\
\text { opinion (gearbox, generator, } \\
\text { towers or blades) [1] }\end{array}$ \\
\hline & $\begin{array}{l}\text { Operating cost at inspection } \\
\text { center plus added disman- } \\
\text { tling cost }\end{array}$ & $\begin{array}{l}{[\$ 1000-\$ 5000] \quad[\$ 35000} \\
\text { added dismantling cost }]\end{array}$ & $\begin{array}{l}\text { Estimated based on expert } \\
\text { opinion (gearbox, generator, } \\
\text { towers or blades) }[1]\end{array}$ \\
\hline & $\begin{array}{l}\text { Operating cost at recycling } \\
\text { center }\end{array}$ & {$[1000-5000]$} & $\begin{array}{l}\text { Estimated based on expert } \\
\text { opinion (gearbox, generator, } \\
\text { towers or blades) }[1]\end{array}$ \\
\hline \multirow{5}{*}{$\begin{array}{l}\text { Installation cost of } \\
\text { centers } \\
\text { Remanufactured tur- } \\
\text { bine } \\
\text { component cost }\end{array}$} & $\begin{array}{l}\text { Inspection, remanufactur- } \\
\text { ing, and recycling centers }\end{array}$ & {$[15000-70000]$} & $\begin{array}{l}\text { Estimated based on expert } \\
\text { opinion [1] }\end{array}$ \\
\hline & $\begin{array}{l}\text { Gearbox } 10-15 \% \text { total cost } \\
\text { of WT }\end{array}$ & $\$ 50000-\$ 75000$ & \multirow[t]{4}{*}[2]{,$[3]$} \\
\hline & $\begin{array}{l}\text { Generator } 5-10 \% \text { total cost } \\
\text { of WT }\end{array}$ & $\$ 25000-\$ 50000$ & \\
\hline & $\begin{array}{l}\text { Tower cost } 10-25 \% \\
\text { cost of } \mathrm{WT}\end{array}$ & $\$ 50000-\$ 125000$ & \\
\hline & $\begin{array}{l}\text { Blades } 10-15 \% \text { total cost of } \\
\text { WT }\end{array}$ & $\$ 50000-\$ 75000$ & \\
\hline \multirow{3}{*}{ Recycling cost profit } & Generator & $\$ 12500$ & \multirow{3}{*}{$\begin{array}{l}\text { Estimated based on typical } \\
\text { materials and quantities } \\
\text { required for Vestas V82 } \\
\text { 1.65-MW turbine. }\end{array}$} \\
\hline & Gear box & $\$ 7000$ & \\
\hline & Tower & $\$ 75600$ & \\
\hline
\end{tabular}

Notes. [1] Renew Energy Maintenance [34]. [2] Oliveira and Fernandes [11]. [3] Repowering Solutions [35]. [4] Sandia National Laboratories [37].

\section{Summary OF NUMERICAL RESUlts}

In this section, we illustrate how the models presented in the previous section can be used to obtain useful insights. The insights, presented in the form of a series of observations, are based on numerical results generated from solving the models for examples of problems with varying parameter values. The details of the experimental setup can be found in Section 4.6.

\subsection{Model 1: Results}

For the Model-1, to investigate the impact of emission control on the reverse logistic network design, several different recycling/remanufacturing ratio were used to analyze the effect of material flow on total emissions and the total network cost. Table 3 presents the output generated by the Model-1. The output variables include total network cost, operating cost for both recycling and remanufacturing facilities, transportation cost for recycling and remanufacturing centers and total emissions associated with operation activities at recycling and remanufacturing centers. It is observed that when the recycling ratio decreases, the operating emissions increases up to $70 \%$ due to the higher emissions rate at the remanufacturing center. The percent contribution of the transportation emissions for recycling and remanufacturing centers stays between 3-17\% and 6-21\%, respectively (see Fig. 1). Therefore, it can be concluded that in addition to operating emissions, transportation emissions are also important factors in the design of a reverse logistics network. Comparing all the scenarios, for 
TABLE 3. Model 1 results summary.

\begin{tabular}{llllllllllll}
\hline \hline \multirow{2}{\text{Scenario}}{$\begin{array}{l}\mathrm{R}-\mathrm{RM} \\
\text { Ratio }\end{array}$} & $\begin{array}{l}\text { Network } \\
\text { Cost }(\$)\end{array}$ & $\begin{array}{l}\text { Operating } \\
\text { Cost R }(\$)\end{array}$ & $\begin{array}{l}\text { Operating } \\
\text { Cost RM }(\$)\end{array}$ & $\begin{array}{l}\text { Trans. Cost } \\
\text { to R }(\$)\end{array}$ & $\begin{array}{l}\text { Trans. Cost } \\
\text { to RM }(\$)\end{array}$ & $\begin{array}{l}\text { Facility } \\
\text { Emissions } \\
(\mathrm{RM})\end{array}$ & $\begin{array}{l}\text { Facility } \\
\text { Emissions } \\
(\mathrm{R})\end{array}$ & $\begin{array}{l}\text { Trans. } \\
\text { Emissions } \\
(\mathrm{RM})\end{array}$ & $\begin{array}{l}\text { Trans. } \\
\text { Emissions } \\
(\mathrm{R})\end{array}$ \\
\hline $\begin{array}{l}0 \text { (base } \\
\text { case) }\end{array}$ & $60 / 30$ & 538339012 & 38556000 & 311760000 & 105046600 & 70031040 & 17507760 & 57629824 & 6426000 & 17133600 \\
\hline 1 & $50 / 40$ & 609852992 & 32130000 & 389700000 & 87538810 & 87538810 & 35015520 & 51544838 & 10852000 & 13278000 \\
\hline 2 & $40 / 50$ & 681367012 & 25704000 & 467640000 & 70031040 & 105046600 & 52523280 & 44819866 & 12278000 & 9422400 \\
\hline 3 & $30 / 60$ & 752880952 & 19278000 & 545580000 & 52523280 & 122554300 & 70031040 & 33614899 & 15704000 & 7366800 \\
\hline 4 & $20 / 70$ & 824394992 & 12852000 & 623520000 & 35015520 & 140062100 & 80538810 & 22409933 & 22130000 & 6511200 \\
\hline 5 & $10 / 80$ & 895909032 & 6426000 & 701460000 & 17507760 & 157569900 & 90046600 & 11204966 & 28556000 & 3855600 \\
\hline
\end{tabular}

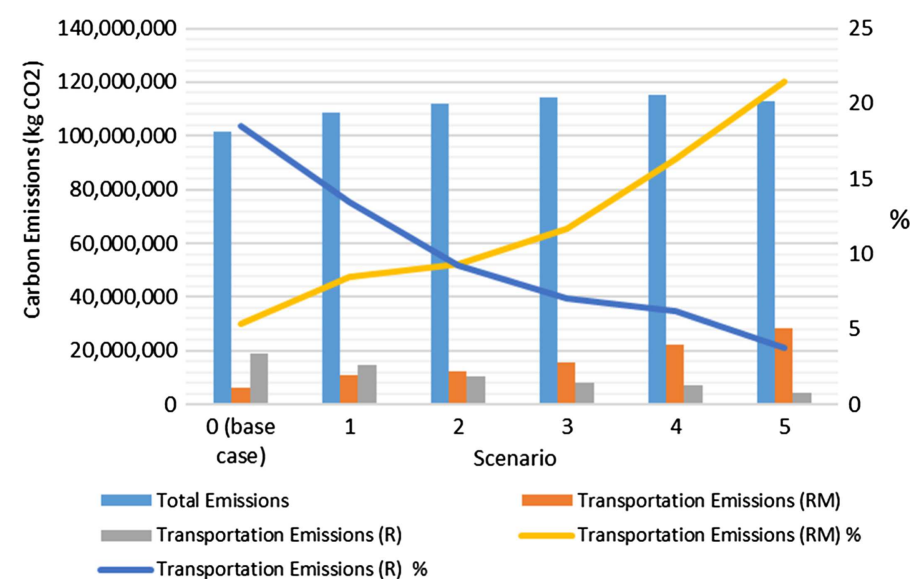

Figure 1. Total emission and transportation emission with \% distribution to total emissions for the remanufacturing operations.

the recycling operation, carbon emissions from the operating activities decreasde to $21 \%$, while carbon emissions from the transportation activities decreased to $7 \%$. For the remanufacturing facility, carbon emissions from the operating activities increased to $59 \%$, while carbon emissions from the transportation activities increased to $7 \%$. This implies that carbon emissions can be reduced through optimal planning of a reverse logistics network.

\subsection{Model 2: Results}

For the Model-2, the impact of carbon cap and carbon credit on reverse logistic network design were investigated under six different recycling/remanufacturing ratio. Table 4 presents the output generated by the Model-2. The output variables include total network cost, operating cost for both recycling and remanufacturing facilities, transportation cost for recycling and remanufacturing centers and total emissions associated operation activities at recycling and remanufacturing centers. Similar to the Model 1, it was observed that with decreasing recycling ratio, operating emissions from the remanufacturing centers increased $70 \%$ during the first three scenarios and operating emissions from the remanufacturing centers decreased $70 \%$ during the last three scenarios (see Fig. 2). As $\mathrm{CO}_{2}$ emissions rate at the recycling centers is less than the remanufacturing centers, at some point, the model prefers recycling over remanufacturing due to cost minimization objective. Providing a carbon credit for every $\mathrm{kg} \mathrm{CO}_{2}$ emissions reduction leads to decrease in the total reverse logistic cost. It is also observed more carbon emissions reduction can be achieved through the implementation of higher carbon cap rate. This is due to applied carbon credit paid for each $\mathrm{kg} \mathrm{CO}_{2}$, which is not emitted. 
TABLE 4. Model 2 results summary.

\begin{tabular}{llllllllllll}
\hline \hline \multirow{2}{\text{Scenario}}{$\begin{array}{l}\mathrm{R}-\mathrm{RM} \\
\text { Ratio }\end{array}$} & $\begin{array}{l}\text { Network } \\
\text { Cost }(\$)\end{array}$ & $\begin{array}{l}\text { Operating } \\
\text { Cost R }(\$)\end{array}$ & $\begin{array}{l}\text { Operating } \\
\text { Cost RM }(\$)\end{array}$ & $\begin{array}{l}\text { Trans. Cost } \\
\text { to RM }(\$)\end{array}$ & $\begin{array}{l}\text { Trans. Cost } \\
\text { to R }(\$)\end{array}$ & $\begin{array}{l}\text { Facility } \\
\text { Emissions } \\
(\mathrm{RM})\end{array}$ & $\begin{array}{l}\text { Facility } \\
\text { Emissions } \\
(\mathrm{R})\end{array}$ & $\begin{array}{l}\text { Trans. } \\
\text { Emissions } \\
(\mathrm{RM})\end{array}$ & $\begin{array}{l}\text { Trans. } \\
\text { Emissions } \\
(\mathrm{R})\end{array}$ \\
\hline $\begin{array}{l}0 \text { (base } \\
\text { case) }\end{array}$ & $60 / 30$ & 533339012 & 38556000 & 311760000 & 70231040 & 104846600 & 14006208 & 63392806 & 6426000 & 14133600 \\
\hline 1 & $50 / 40$ & 539852992 & 31130000 & 389700000 & 87638810 & 86538810 & 28012416 & 56699322 & 10952000 & 13178000 \\
\hline 2 & $40 / 50$ & 545367012 & 24704000 & 467640000 & 105846600 & 69031040 & 42018624 & 49301852 & 12778000 & 11222400 \\
\hline 3 & $30 / 60$ & 534880952 & 29178000 & 445580000 & 103554300 & 71523280 & 40024832 & 52976389 & 11904000 & 10466800 \\
\hline 4 & $20 / 70$ & 522394992 & 32652000 & 423520000 & 101062100 & 72015520 & 37431048 & 55650926 & 11830000 & 12211200 \\
\hline 5 & $10 / 80$ & 520394992 & 36126000 & 401460000 & 98569900 & 76507760 & 32037280 & 54325463 & 10272600 & 13041160 \\
\hline
\end{tabular}

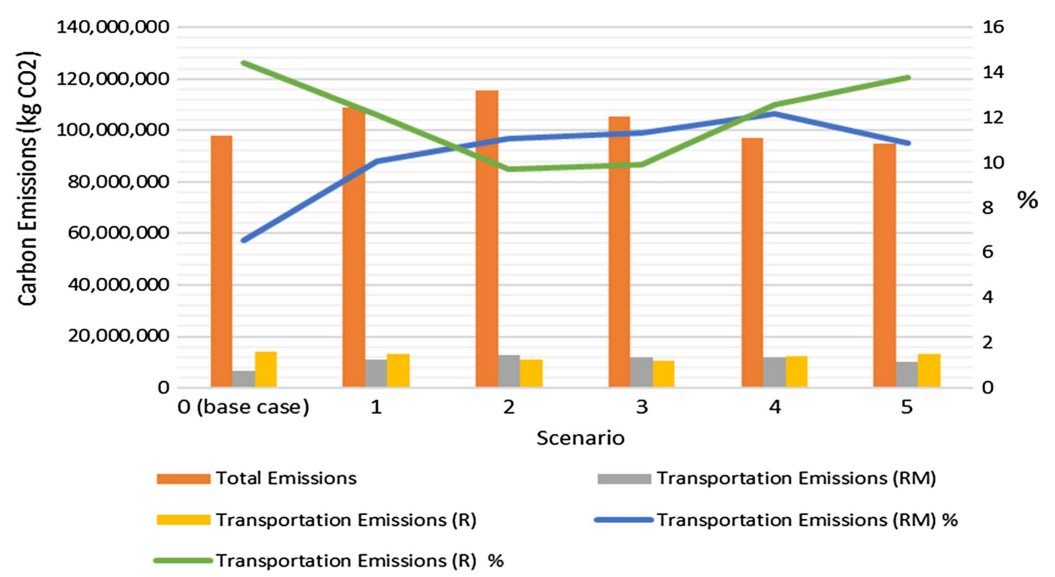

FIGURE 2. \% Emission contribution at recycling and remanufacturing operations for each scenario.

\section{Sensitivity AnALYSiS}

The purpose of the sensitivity analysis is to investigate the influences of those key parameters on operating costs and carbon emissions of the reverse logistics network. It is clear that there is a relationship between total carbon emissions, operating emission rates of recycling and remanufacturing centers, carbon cap, and carbon credit. Therefore, a sensitivity analysis was performed to see the effect of carbon cap and carbon credit on the total carbon emissions.

\subsection{Model 1: Sensitivity}

\subsubsection{Increasing emission rate at remanufacturing centers}

In the first sensitivity analysis for the Model 1, the emission rate (i.e., 10\%, 20\%, and 30\%) at remanufacturing centers was increased in the interval of 10 and the other parameters remain the same. Figure 3 presents the output generated by the sensitivity analysis. The total carbon emission begins relatively high and continues to decrease with increasing emittion rate. Sensitivity analysis showed that as model tries to optimize both cost and the carbon emissions, once we increased the emission rate at the remanufacturing centers, the model prefers to send more flow to recycling centers, which has low operating cost and low carbon emissions rate. Therefore, there an increase is observed in transportation and operating emissions at recycling centers whereas a decrease is observed in transportation and operating emissions at remanufacturing centers. 


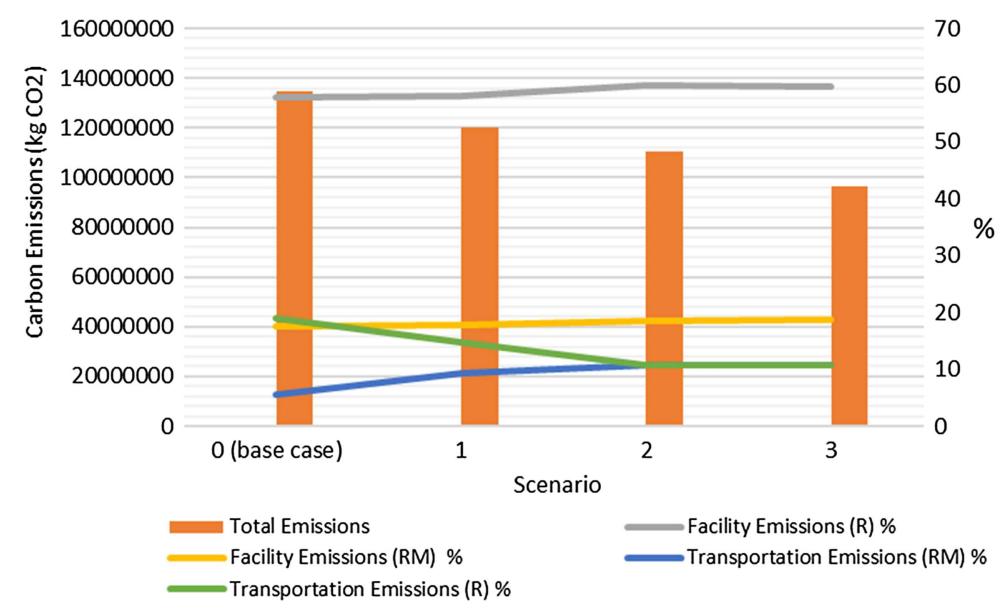

FIGURE 3. Sensitivity analysis results for increasing emission rate at recycling center.

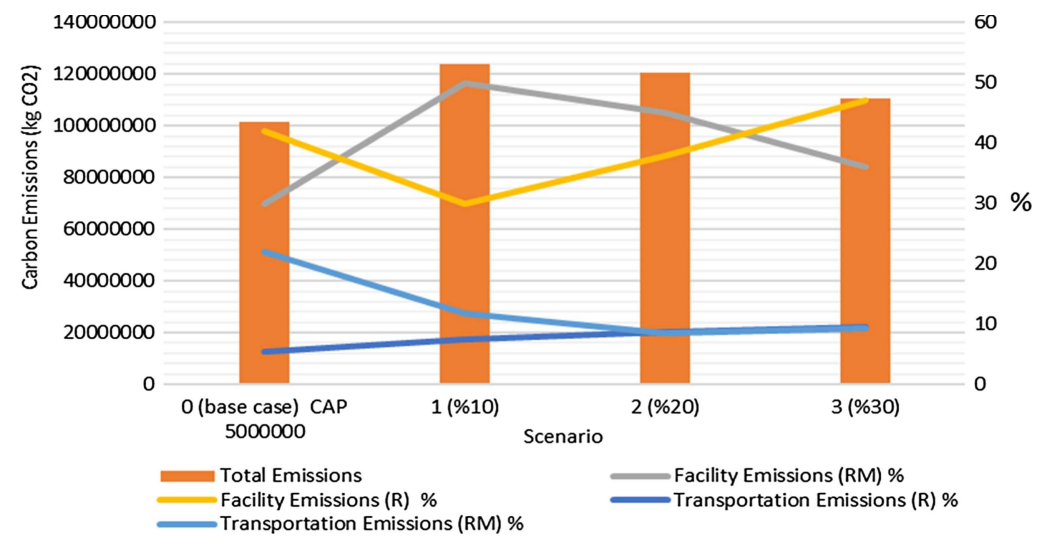

Figure 4. Model 1-Sensitivity analysis results for increasing cap rate.

\subsubsection{Increasing carbon cap rate}

In the second sensitivity analysis for the Model 1, the carbon cap rate was increased by $10 \%, 20 \%$ and $30 \%$. As a result, the total emission increased by more than $20 \%$. The carbon cap rate for the base case was selected to be $500000 \mathrm{~kg} \mathrm{CO}$. This analysis indicates that in the assumed case, if the carbon cap rate was flexed, the model acts as if there is no carbon limiting constraint exist and the model prefers sending most of the material to the remanufacturing centers (see Fig. 4). Therefore, the total increase in total carbon emissions was due to the high operating carbon emissions at remanufacturing centers.

\subsection{Model 2: Sensitivity analysis}

In the sensitivity analysis for the Model 2, we are interested in how the carbon cap and carbon credit influences decision-making in a reverse logistics network design and three scenarios with incremental carbon cap and carbon credit rate (i.e., 10\%, 20\%, and 30\%) are investigated. 


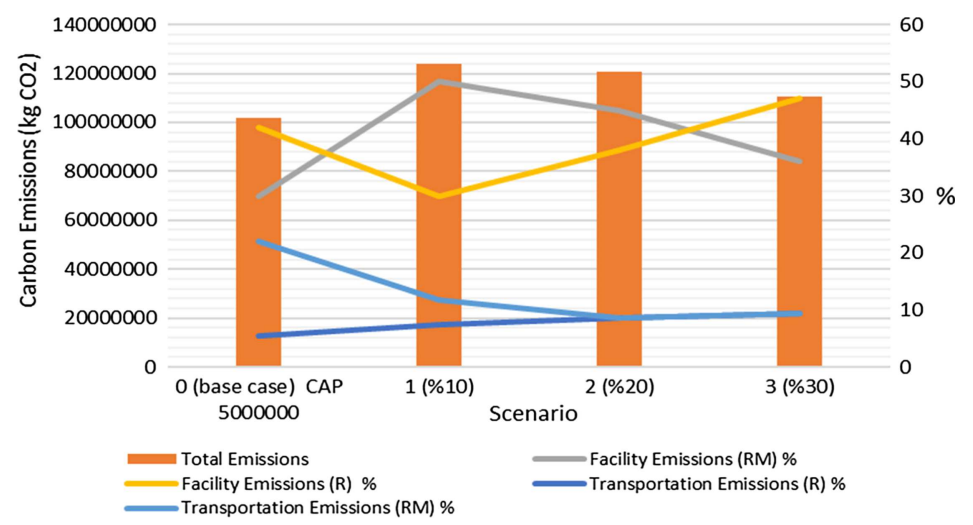

FiguRE 5. Model 2-Sensitivity analysis results for increasing cap rate.

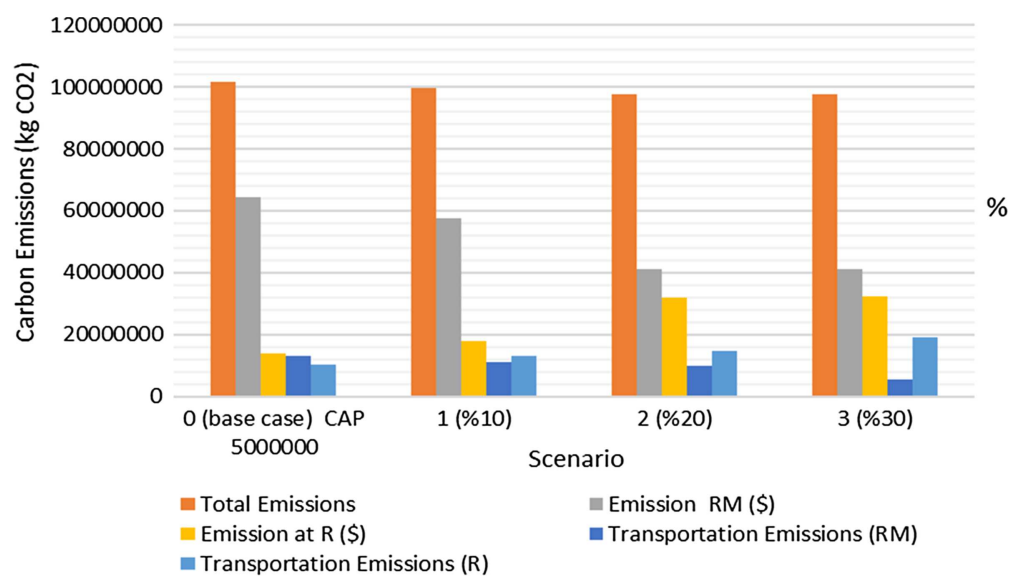

Figure 6. Model 2-Sensitivity analysis results for increasing credit amount.

\subsubsection{Increasing carbon cap rate}

In the first sensitivity analysis for the Model 2, the cap rate (i.e., 10\%, 20\%, and 30\%) was decreased in the interval of 10 and the other parameters remain the same. The sensitivity analysis showed (see Fig. 5) that once we decreased the cap rates at a certain level, as model tried to optimize both cost and the carbon emissions, the model the preferred to send more flow to recycling centers, which has lower operating cost and lower emission rates. When carbon cap is relatively high, the model was mostly sending most of the material to remanufacturing centers. When the carbon cap was sufficiently low, the model started sending most of the material to recycling centers, as the model finds it advantageous to adjust its operations and emit less carbon.

\subsubsection{Increasing carbon credit rate}

In the second sensitivity analysis for the Model 2, the carbon credit rate (i.e., 10\%, 20\%, and 30\%) was increased in the interval of 10 and the other parameters remain the same. Sensitivity analysis showed (see Fig. 6) that increasing carbon credit rate, the total carbon emissions decreases by $2 \%$ for the $10 \%$ and a $20 \%$ increase, respectively and for the $30 \%$ increase, the increase is only $0.1 \%$. This means that increasing carbon credit rate may not be enough by itself. Therefore, along with carbon credit rate, increasing or decreasing of carbon cap rate may be effective to reach the minimum cost and minimum emission for the system. 
Comparing the results of these different scenarios show that this current reverse logistics network fits all scenarios quite well, with the potential to be adjusted to fit the strategic change of recycling and remanufacturing options to optimize the total network cost and total carbon emissions. It was observed that emissions can be directly controlled by varying the carbon cap rate and carbon price. Therefore, the resulting emissions can be controlled by adjusting these parameters to reach the optimum cost and emission values for the reverse logistic network. Applying different carbon cap and carbon credit rates as well as different recycling and remanufacturing rates will provides guidance in decision making by quantifying the difference, in terms of total network cost and total carbon emissions of reverse logistics of WTs.

\section{Conclusions AND FURTher ReSEARCH}

In recent years, reverse logistics has been increasingly focused in order to capture the remaining values from used products through recycling and remanufacturing. A significant number of previous studies have focused on both theoretical development and mathematical modeling of reverse logistics problems. This paper has presented a mathematical model includes two objectives (1) minimization of overall reverse logistics costs, and (2) minimization of carbon emissions of the transportation and processing of used products. To the best of our knowledge, this paper is the first to study the RLN designed for EOL WT considering environmental factors (i.e, carbon cap and carbon credit rates). Therefore, the most significant contribution of this study is to take into account of environmental factors in order to improve both economic and environmental sustainability of reverse logistics in the field of WT industry. The proposed model will help the decision maker to choose the most suitable disposal method with the remanufacturing and recycling alternatives by considering the environmental impact of each disposal alternative. Together with a baseline run of the current situation, various scenarios are modeled. The results of this study show that due to the high operating emission rate at remanufacturing center, sending most WTs to remanufacturing centers has more environmental effect than sending them to recycling centers. In addition, it was shown that transportation emissions depend on the amount of flow that has been sent to the recycling or remanufacturing center. Two major carbon control policies are involved in this study, carbon cap and carbon credit scheme. The carbon cap approach has a fixed number of annual allowances allocated to the participants as a cap. The carbon credit approach is allowing participants to sell their surplus allowances for a profit. To identify potential business reactions or behavior with government carbon control policies, the analysis is performed with different carbon credit rates as sensitivity analysis through the optimization model. For carbon cap policy, different carbon limits are used in the analysis. The analysis with the optimization model uses different rates of carbon credit so that the sensitivity of the reverse logistic network performance of the carbon policy can be reserved.

In summary, the computer results and analysis yielded the following conclusions:

(i) The rate of carbon cap and carbon credit is clearly an important factor in selecting different disposal options for EOL WTs. The results shows (demonstrate that) low emission cap leads to higher total emissions limit. With carbon credit increasing in the amount of emissions that exceed the cap, the system is penalized for doing so, with penalties. Companies are also rewarded for emitting less than their cap by receiving payments increasing in the difference between their cap and their actual emissions.

(ii) It was determined that besides operating emissions, transportation emissions plays important role on total carbon emissions.

As the price of carbon emissions is affected by market dynamics and the total amount of carbon that can be bought and sold is limited by the sum of the cap imposed by the government, these factors can be also analyzed to see the difference market conditions. As such, in order to extend the current MILP formulation, the following additions to the model have been proposed for future work:

- It would be useful to carry out empirical work that can be used to validate or enrich the results from the analytical models. For example, there is already carbon emission control legislation that has been in place in various countries, such as those in the EU, for several years now. It might be possible to further document 
the impact this legislation has had on the operations of various firms in those countries and on emission levels and carbon prices. In particular, it would be useful to identify the types of operational adjustments that firms have made in response to climate control legislation and the impact these adjustments have had on emissions and cost. It would also be of interest to compare how differences in legislation from country to country (e.g., those that have adopted a carbon tax versus those with a cap-and-trade system) have affected differently operational decisions made in those countries.

- While our approach with the available information provided good solutions that certainly, improve decisionmaking to accommodate uncertainties in data, either a stochastic MILP model or a Stochastic Dynamic Programming model could be developed for current problem.

- Our approach takes into consideration environmental factors as to evaluate dynamic situations. Instead, proposed model can be modified as a multi-objective problem to trade-off between cost and environmental objective. In addition, there can be interest to social effects into the objective function.

Real-world reverse logistic network design for WTs are typically more complicated than the hypothetical test case considered in this paper. During the decision-making process, technical, economic and legal aspect of each option should be considered. With respect to the legal aspect in terms of Cap-and-trade policy, there are several country-specific uncertainties such as subsidy schemes, legal requirements, future demand for wind energy, wind energy prices, etc., that were not taken into account by the model presented here and can be considered as managerial implications. Due to impact of these uncertainties, it is necessary for companies to restructure their supply chains in terms of strategic and operational decisions to meet the targeted emissions.

It can be concluded that the trade-off between system operating costs and environmental impacts of reverse logistics activities, and it has also provided decision makers with deep managerial insights of the interactions among different parameters in the reverse logistics network design.

\section{REFERENCES}

[1] B.A. Alkhayyal and S.M. Gupta, The impact of carbon emissions policies on reverse supply chain network design. Doğu̧̧ Üniversitesi Dergisi 19 (2018) 99-111.

[2] S.H. Anvar, A. Sadegheih and M.A.V. Zad, Carbon emission management for greening supply chain at the operation level. Environ. Eng. Manage. J. (EEMJ) 17 (2018) 1337-1347.

[3] A. Arvesen and E. Hertwich, Assessing the life cycle environmental impacts of wind power: a review of present knowledge and research needs. Renew. Sustainable Energy Rev. 16 (2012) 5994-6006. Assessing the life cycle environmental impacts of wind power: A review of present knowledge and research needs.

[4] AU, Waste Management of End-of-service Wind Turbines. Available from: https://projekter.aau.dk/projekter/files/ 213319772/Waste_management_of_end_of_service_wind_turbines.pdf (2015) [cited March 15, 2016].

[5] S. Benjaafar, Y. Li and M. Daskin, Carbon footprint and the management of supply chains: insights from simple models. IEEE Trans. Automot. Sci. Eng. 10 (2013) 99-116.

[6] J. Bloemhof-Ruwaarda, A. Chaaba and X. Binga, Global reverse supply chain redesign for household plastic waste under the emission trading scheme. J. Cleaner Prod. 103 (2015) 28-39.

[7] E. Bottani and G. Casella, Minimization of the environmental emissions of closed-loop supply chains: A case study of returnable transport assets management, Sustainability 10 (2018) 1-20.

[8] X. Chen and X. Wang, Effects of carbon emission reduction policies on transportation mode selections with stochastic demand. Transp. Res. Part E: Logistics Transp. Rev. 90 (2016) 196-205.

[9] A. Choudhary, S. Sarkar, S. Settur and M. Tiwa, A carbon market sensitive optimization model for integrated forward-reverse logistics. Int. J. Prod. Econ. 164 (2015) 433-444.

[10] S. Cinar and M. Yildirim, Reverse logistic network design for end-of-life wind turbines. In: Optimization and Dynamics with Their Applications, edited by M. A içinde. Springer, Singapore. (2017).

[11] W.S. de Oliveira and A. Fernandes, Cost analysis of material composition of the wind turbine blades for Wobben Windpower/ENERCON GmbH Model E-82. Cyber J.: Multi. J. Sci. Technol. J. Select. Areas Renew. Energy (JRSE) (2012) 1-7.

[12] A. Diabat, and M. Al-Salem, An integrated supply chain problem with environmental considerations. In: Advances in Sustainable Manufacturing. Springer, Berlin, Heidelberg (2015) 330-338.

[13] S. Du, L. Hu and M. Song, Production optimization considering environmental performance and preference in the cap-and-trade system. J. Cleaner Prod. 112 (2016) 1600-1607.

[14] ECTA, Guidelines for Measuring and Managing $\mathrm{CO}_{2}$ Emission From Freight Transport Operations. Available from: https://www.ecta.com/resources/Documents/Best\%20Practices\%20Guidelines/guideline_for_measuring_and_managing_ co2.pdf (2011) [cited March 12, 2018]. 
[15] B. Eleonora and G. Casella, Minimization of the environmental emissions of closed-loop supply chains: a case study of returnable transport assets management. Sustainability 10 (2018) 329.

[16] X. Fang, Y. Du and Y. Qiu, Reducing carbon emissions in a closed-loop production routing problem with simultaneous pickups and deliveries under carbon cap-and-trade. Sustainability 9 (2017) 2198.

[17] R. Geyer and T. Jackson, Supply loops and their constraints: the industrial ecology of recycling and reuse. California Manage. Rev. 46 (2004) 55-73.

[18] C. Ghenai, Life Cycle Analysis of Wind Turbine. Ocean and Mechanical Engineering Department, Florida Atlantic University. Available from: http://cdn.intechopen.com/pdfs/29930.pdf (2012) [cited April 24, 2018].

[19] A. Ghosh, S. Sarmah and J. Jha, Collaborative model for a two-echelon supply chain with uncertain demand under carbon tax policy. Sādhanā 43 (2018) 144.

[20] Goldstandard, Available from: https://www.goldstandard.org/blog-item/carbon-pricing-what-carbon-credit-worth (2018).

[21] K. Haapala and P. Prempreeda, Comparative life cycle assessment of $2.0 \mathrm{MW}$ wind turbines. Int. J. Sustainable Manuf. 3 (2014) 170-185.

[22] Helpsavenature, Available from: https://helpsavenature.com/carbon-credits-price (2018). [cited May 14, 2017].

[23] W. Hulshorst, Repowering and Used Wind Turbines. Leonardo Energy. Available from: http://www.leonardo-energy.org/ sites/leonardo-energy/files/root/pdf/2008/repowering-wind.pdf (2008) [cited June 20, 2016].

[24] J. Humberto Ablanedo-Rosas, P. Fu and Y. Peng, A multiperiod supply chain network design considering carbon emissions. Math. Prob. Eng. 2016 (2016) 1-11.

[25] M. Jaber, C. Glock and A. El Saadany, Supply chain coordination with emissions reduction incentives. Int. J. Prod. Res. 51 (2013) 69-82.

[26] B.-R. Jacqueline, A. Chaa and X. Bing, Global reverse supply chain redesign for household plastic waste under the emission trading scheme. J. Cleaner Prod. 103 (2015) 28-39.

[27] W. Jiang and X. Chen, Optimal strategies for manufacturer with strategic customer behavior under carbon emissions-sensitive random demand. Ind. Manage. Data Syst. 116 (2016) 759-776.

[28] H. Krikke, A. van Harten and P. Schuur, Business case Océ: reverse logistics network re-design for copiers. OR Spektrum 21 (1999) 381-409.

[29] Longitude Store.com, The Haversine Formula. Available from: http://www.longitudestore.com/haversine-formula.html (2014) [cited June 10, 2018].

[30] Z. Luo, X. Chen and X. Wang, The role of co-opetition in low carbon manufacturing. Eur. J. Opera. Res. 253 (2016) $392-403$.

[31] A. Partridge, Full Circle: Reverse Logistics Keeps Products Green to the End. Available from: https://www . inboundlogistics . com/cms/article/full-circle-reverse-logistics-keeps-products-green-to-the-end/ (2011) [cited September 17, 2018].

[32] W. Post, Energy from wind turbines actually less than estimated? The Energy Collective. Available from: http://www. theenergycollective.com/willem-post/169521/wind-turbine-energy-capacity-less-estimated (2013) [cited September $11,2018]$.

[33] A. Purohit, R. Shankar and P. Kumar, Non-stationary stochastic inventory lot-sizing with emission and service level constraints in a carbon cap-and-trade system. J. Cleaner Prod. 113 (2016) 654-661.

[34] Renew Energy Maintenance, Available from: http://www.renewenergy.com/ (2012) [cited March 17, 2016].

[35] Repowering Solutions, Remanufactured wind turbines - New opportunities for the wind industry. Available from: http: //www.repoweringsolutions.com/english/sales_brochure/Brochure_refurbished_wind_turbines.pdf (2011) [cited March $13,2017]$.

[36] A. Rezaee, F. Dehghanian and B. Fahimnia, Green supply chain network design with stochastic demand and carbon price. Ann. Oper. Res. 252 (2017) 463-485.

[37] Sandia National Laboratories, Cost study for large wind turbine blades: WindPACT blade system design studies. Sand Report. Available from: http://windpower.sandia.gov/other/031428.pdf (2003) [cited March 17, 2017].

[38] C. Rydh, M. Jonsson and P. Lindahl, Replacement of Old Wind Turbines Assessed From Energy, Environmental and Economic Perspectives. Available from: http://citeseerx.ist.psu.edu/viewdoc/download?doi=10.1.1.524.8291andrep=rep1andtype= pdf (2004) [cited September 15, 2018].

[39] SEA, Carbon Trading-Literature Overview. Available from: http://www.seo.nl/uploads/media/2010-65__Carbon_Trading. pdf (2010) [cited July 17, 2018].

[40] SEO, Carbon Trading- Literature Review. Available from: http://www.seo.nl/uploads/media/2010-65__Carbon_Trading.pdf (2010) [cited June 10, 2018].

[41] S. Skrainka, Analysis of the environmental impact on remanufacturing wind turbines. Master's thesis, Rochester Institute of Technology (2012).

[42] E. Smoucha, K. Fitzpatrick, S. Buckingham and O. Knox, Life cycle analysis of the embodied carbon emissions from 14 wind turbines with rated powers between $50 \mathrm{Kw}$ and 3.4 Mw. J. Fundam. Renew. Energy Appl. 6 (2016) 211.

[43] Z. Xu, A. Elomri, S. Pokharel and Q. Zhang, Global reverse supply chain design for solid waste recycling under uncertainties and carbon emission constraint. Waste Manage. 64 (2017) 358-370.

[44] H. Yu and W. Solvang, A general reverse logistics network design model for product reuse and recycling with environmental considerations. Int. J. Adv. Manuf. Technol. 87 (2016) 2693-2711.

[45] B. Zhu and Y. Wei, Carbon price forecasting with a novel hybrid ARIMA and least squares support vector machines methodology. Omega 41 (2013) 517-524. 